\title{
Molecular Mechanism to Maintain Stem Cell Renewal of ES Cells
}

\author{
Hitoshi Niwa ${ }^{1,2 *}$ \\ ${ }^{1}$ Stem Cell Regulation Research, Area of Molecular Therapeutics, Course of Advanced Medicine, Osaka Uni- \\ versity Graduate School of Medicine, Yamadaoka 2-2, Suita C., Osaka 565-0871, Japan, and ${ }^{2}$ Laboratory of \\ Pluripotent Cell Studies, RIKEN Center for Developmental Biology
}

\begin{abstract}
Embryonic stem (ES) cells are pluripotent cells directly derived from early stage embryos that retain the ability to differentiate into all cell types. This unique feature is the basis of various applications of ES cell technology such as in vitro models of mammalian development, germline transgenesis to make knockout mice, and a generic source for cell therapy in regenerative medicine. To achieve success in these applications, the pluripotency of ES cells has to be kept stable during long-term culture in vitro, leading to the necessity of determining the molecular basis for maintaining ES self-renewal. This paper summarizes the recent progress in this area, focusing mainly on the LIF signaling pathway and the transcription factor Oct-3/4. Although it is still unclear how these components works together, a model is presented here that provides a plan to solve this problem.
\end{abstract}

Key words: ES cell/pluripotency/LIF/Stat3/Oct-3/4

Cellular pluripotency can be defined as the ability of a cell to differentiate into various types of cells and belongs to all definitive tissues: ectoderm, mesoderm, and endoderm. In mammalian development, only particular subsets of cells in the early stage embryos transiently possess pluripotency. Therefore, it is difficult to characterize pluripotency in vivo because of inaccessibility due to small embryo size and in utero development after implantation. Embryonic stem (ES) cells are directly derived from such pluripotent cell populations and can maintain pluripotency under particular culture conditions in vitro (reviewed by Smith, 1992). Thus, they can provide a good model system to analyze molecular mechanism to maintain cellular pluripotency (reviewed by Pesce et al., 1999). Recent progress on the study of signal transduction and transcriptional regulation supporting stem cell renewal of ES cells is reviewed in this report.

\footnotetext{
*To whom correspondence should be addressed: Laboratory of Pluripotent Cell Studies, RIKEN Center for Developmental Biology, MinatojimaMinamimachi 2-2-3, Chu-o-ku, Kobe 650-0047, Japan.

Tel: +81-78-306-0156, Fax: +81-78-306-0101

E-mail: niwa@rtc.riken.go.jp

Abbreviations: ES, embryonic stem; LIF, leukemia inhibitory factor; GCSF, granulocyte colony stimulating factor; ESRF, ES renewal factor; ICM, inner cell mass; EC, embryonal carcinoma; PEC, primitive ectoderm; FGF, fibroblast growth factor; PDGF, platelet-derived growth factor; hCG, human chorionic gonadotropin; ELA, E1A-like activity; EG, embryonic germ.
}

\section{Exogenous signal to maintain ES self-renewal}

Leukemia inhibitory factor (LIF) is a cytokine belonging to the IL-6 family which was initially identified by its activity to induce differentiation of M1 leukemia cells (Tomida et al., 1984; Gearing et al., 1987). However, it was re-discovered as an activity to inhibit differentiation of mouse ES cells (Smith et al., 1988; Williams et al., 1988). Addition of LIF is sufficient to establish and maintain ES cells without feeder cells in the presence of fetal calf serum (Nichols et al., 1990), indicating that this is an unique extrinsic factor specifically required for ES self-renewal. LIF function is mainly limited to prevent differentiation, and a previous report indicated that stimulation of proliferation could be separated from LIF action (Raz et al., 1999). Since the analysis of the LIF signal transduction pathway was conducted in M1 cells (reviewed by Hirano et al., 1997), studies in ES cells followed that sought to identify the difference that mediates the opposite cellular responses, which inhibits differentiation in ES cells while inducing differentiation in M1 cells.

\section{Signal transduction of LIF}

The LIF receptor consists of the LIF-specific receptor subunit LIFR $\beta$ and the common signal transducer gp130, which is shared between the members of the IL- 6 cytokine family (reviewed by Taga and Kishimoto, 1997). Since 
LIFR $\beta$ possess an intracellular domain homologous to that of gp130, the roles of these subunits on signal transduction were investigated. Using the chimeric molecules consisting of an extracellular domain of human granulocyte colony stimulating factor (GCSF) and an intracellular domain of either LIFR $\beta$ or gp130, it was clearly shown that LIFR $\beta$ is not sufficient to mediate the signal to maintain ES selfrenewal whereas gp130 is (Starr et al., 1997; Niwa et al., 1998). Indeed, activation of gp130 by the combination of IL-6 with soluble IL-6 receptor can support establishment of ES cell lines and maintain them (Nichols et al., 1994; Yoshida et al., 1994).

There are two major pathways of intracellular signal transduction downstream of gp130 in M1 leukemia cells (reviewed by Hirano et al., 2000), the Jak-Stat pathway and the Shp2-Erk pathway. GCSF-gp130 chimeric receptors, which carry various deletions in the intracellular domain, were assayed for their ability to support ES self-renewal (Matsuda et al., 1999; Niwa et al., 1998). Since Jak and Shp2 interact with separate subdomains of the intracellular domain of gp130, variant chimeric receptors which can recruit only one of them can be generated, and the results clearly showed that activation of Jak, but not Shp2, is sufficient. The role of Stat3, which mainly acts in the LIF signaling pathway in M1 cells, was then tested using a dominant-negative mutant of Stat3 (Stat3F) (Minami et al., 1996; Nakajima et al., 1996). Overproduction of Stat3F in ES cells resulted in induction of differentiation in the presence of LIF, the morphological change of which is similar to that induced by withdrawal of LIF, indicating that activation of Stat 3 is essential to the LIF signaling pathway (Niwa et al., 1998; Starr et al., 1997). Moreover, activation of Stat 3 without LIF is sufficient for it, which was elegantly proved by Matsuda et al. (Matsuda et al., 1999). They made a chimeric protein consisting of Stat 3 and the variant ligand binding domain of estrogen receptor and introduced it into ES cells. This mutant Stat3 (Stat3ER) can be dimerized by addition of estrogen-derivative 4-hydroxy tamoxifen (4-HT), and the ES cells expressing them can be maintained by 4-HT without LIF while maintaining germline competency.

Shp2 signal pathway is not essential for ES self-renewal, but can still act as a modifier of the LIF signal. Shp2 mutant ES cells exhibited a lower magnitude of LIF dependency than wild-type ES cells (Qu and Feng, 1998; Saxton et al., 1997), and the addition of the Erk kinase inhibitor PD98059 in the medium resulted in a similar phenotype (Burdon et $a l .$, 1999a). Thus, the LIF signal is mainly transmitted to the nuclei by the Jak-Stat pathway, and the Shp2-Erk pathway does not contribute directly to stem cell self-renewal (reviewed by Burdon et al., 1999b).

\section{LIF-independent signal: ESRF}

Although activation of Stat3 via gp130 by LIF-related cytokines is sufficient for derivation and maintenance of ES cells (Nichols et al., 1994; Yoshida et al., 1994), there is no direct evidence indicating the importance of this cascade for keeping pluripotent cell population in vivo. It was reported that all of Lif (Stewart et al., 1992), Lifr $\beta$ (Li et al., 1995; Ware et al., 1995), gpl30 (Yoshida et al., 1996), and Stat3 (Takeda et al., 1997) knockout mice can develop beyond the egg cylinder stage. Why is such a discrepancy evident in LIF function in vivo and in vitro? One possible hypothesis is there is an unknown cascade which is functionally redundant to LIF signaling. Indeed, Dani et al. reported that ES cells lacking both endogenous LIF alleles still produce activity to support the undifferentiated state of ES cells in the absence of exogenous LIF after differentiation to parietal endoderm-like cells. They defined this activity as ES renewal factor (ESRF) (Dani et al., 1998). ESRF can maintain the pluripotency of ES cells during a week without LIF. Interestingly, ESRF does not activate Stat3, indicating the presence of an alternative intracellular signaling pathway to maintain stem cell renewal.

\section{Function of Oct-3/4 in ES cells}

Stat3 acts as a transcription factor to activate target genes, which should include essential genes to maintain pluripotent cell phenotype. To date, there are only a few genes identified whose functions are essential to establish or maintain pluripotent cell population in pre- and early postimplantation embryos (reviewed by Pesce et al., 1999). Moreover, in many cases, the phenotype may reflect their housekeeping function in proliferating cells rather than a specific function on pluripotent cell phenotype. For example, outgrowth of the inner cell mass (ICM) was perturbed in $B$-myb (Tanaka et al., 1999) or Chkl (Takai et al., 2000) mutant blastocyst, but it looks more like growth arrest of ICM rather than the disruption of the molecular machinery to maintain pluripotent phenotype because of their broad expression during embryogenesis and proposed general function. There is only one gene whose specific function in pluripotent cell population is confirmed, that is the POU-family transcription factor $O c t-3 / 4$ (also known as Oct-3 or Oct-4, encoded by Pou5f1). Oct-3/4 was initially identified as a POU family member expressed in embryonal carcinoma (EC) cells (Rosner et al., 1990; Schöler et al., 1990a) or a transcriptional regulator binding to the retrotransposon enhancer which showed undifferentiated state-specific activity in EC cells (Okamoto et al., 1990). Oct-3/4 expression is tightly restricted in totipotent and pluripotent cells in mouse life cycle (Fig. 1) (reviewed in Pesce et al., 1998a). Expression was observed in oocytes, early cleavage stage embryos, the ICM of the blastocyst, primitive ectoderm (PEC) in egg cylinder stage embryos, and primordial germ cells (Palmieri et al., 1994; Schöler et al., 1990b), suggesting its important role in maintaining cellular pluripotency. One exceptional loss of Oct-3/4 in 


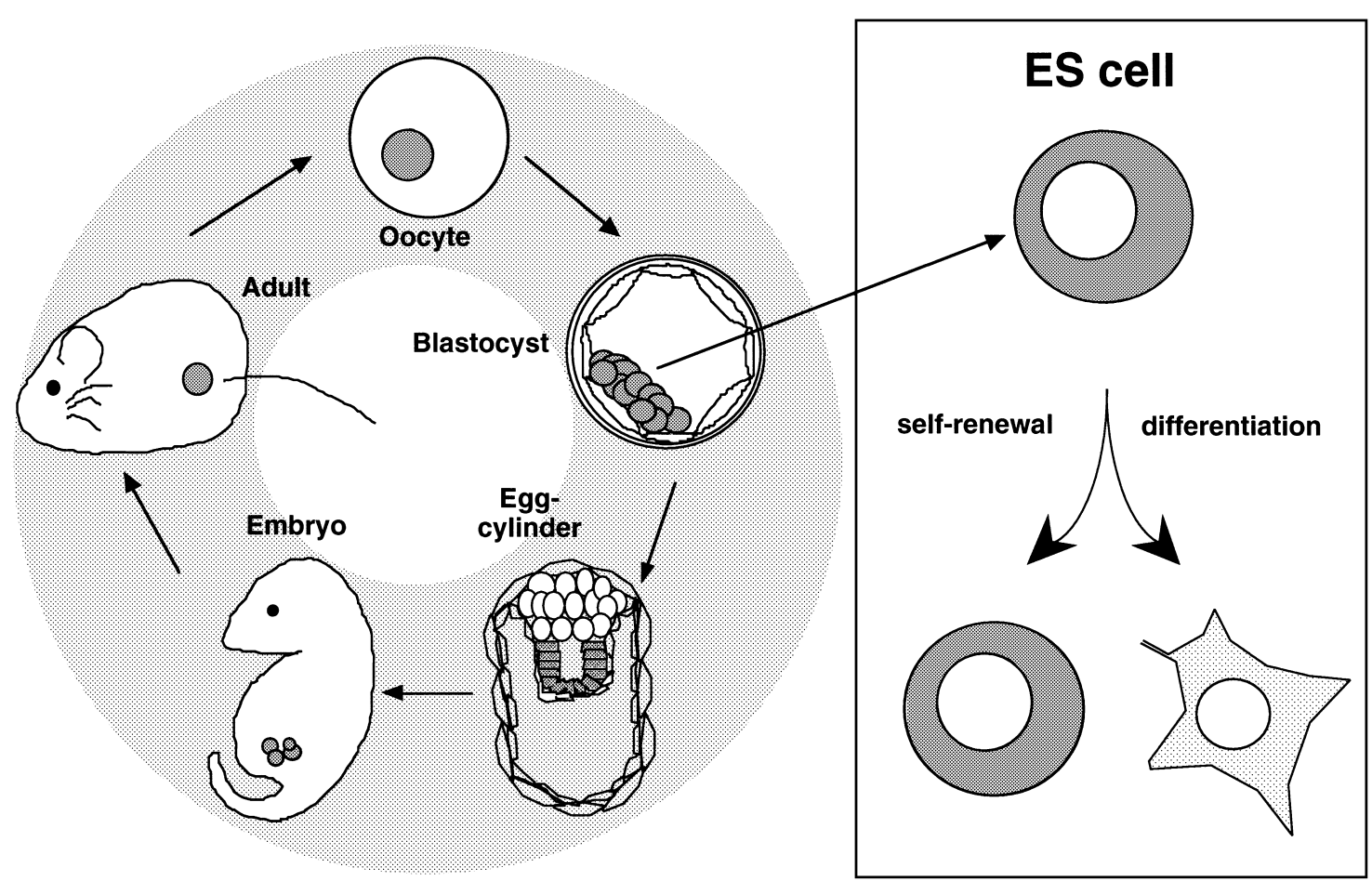

Fig. 1. Stem cell-specific expression of Oct-3/4. Oct-3/4 expression is seen in fertilized eggs, inner cell mass of blastocyst, primitive ectoderm in egg cylinder, and primordial germ cells in later stage embryo and germ cells in adult. It also expresses in a stem cell-specific manner in mouse ES cells cultured in vitro.

pluripotent cell population can be found during oogenesis and spermatogenesis coincident with entry into meiosis (Pesce et al., 1998b). Furthermore, the up-regulation in oocyte at the completion of prophase I of meiotic division is evident in ovary whereas Oct-3/4 expresses only in type A spermatogonia in testis, indicating specific role of Oct-3/4 in oocyte growth (Pesce et al., 1998b).

The essential role of Oct-3/4 in mouse development has been revealed by targeting gene deletion (Nichols et al., 1998). Oct-3/4 deficient embryos fail to initiate fetal development because the prospective founder cells of the ICM do not acquire pluripotency and become diverted into the trophectoderm lineage, indicating Oct-3/4 is essential to establish pluripotent cell population in preimplantation development. Further investigation via conditional repression/expression in ES cells has revealed that the precise level of Oct-3/4 governs three different cell fates (Niwa et al., 2000). ES cells require a critical level of Oct-3/4 to maintain stem cell renewal, and a less than twofold increase causes differentiation into endoderm and mesoderm whereas reduction to less than $50 \%$ of the normal expression level triggers dedifferentiation into trophectoderm (Fig. 2) (Niwa et al., 2000). In the presence of fibroblast growth factor (FGF)-4 and feeders, it is even possible to isolate trophoblast stem (TS) cells (Tanaka et al., 1998) from ES cells by repression of Oct-3/4 expression (Niwa et al., 2000). These observations not only accord with the expression pattern in preimplantation embryos, in which Oct-3/4 is up-regulated in primitive endoderm and down-regulated in trophectoderm (Palmieri et al., 1994), but also fit the phenotype of Oct-3/4-null embryos (Nichols et al., 1998). Therefore, Oct-3/4 can be regarded as a candidate for master regulator of initiation, maintenance and differentiation of pluripotent cells.

Does Stat3 keep cellular pluripotency via activation of Oct-3/4? This simple hypothesis is now ruled out because keeping the expression of Oct-3/4 at appropriate levels cannot prevent differentiation of ES cells induced by withdrawal of LIF (Niwa et al., 2000). However, the upregulation of Oct-3/4 induces a differentiation event which is quite similar to that induced by withdrawal of LIF (Niwa et al., 2000). To investigate the relationship between these differentiation events, it is necessary to inquire into the molecular mechanism of Oct-3/4 function in detail.

\section{How Oct-3/4 works in ES cells}

\section{Target genes}

A few target genes of Oct-3/4 have been identified to date, and the Oct-3/4 binding sites confirmed in their regulatory elements are listed in Fig. 3 (Nishimoto et al., 1999; Ben-Shushan et al., 1998; Botquin et al., 1998; Kraft et al., 1996; Liu and Roberts, 1996; Saijoh et al., 1996; 


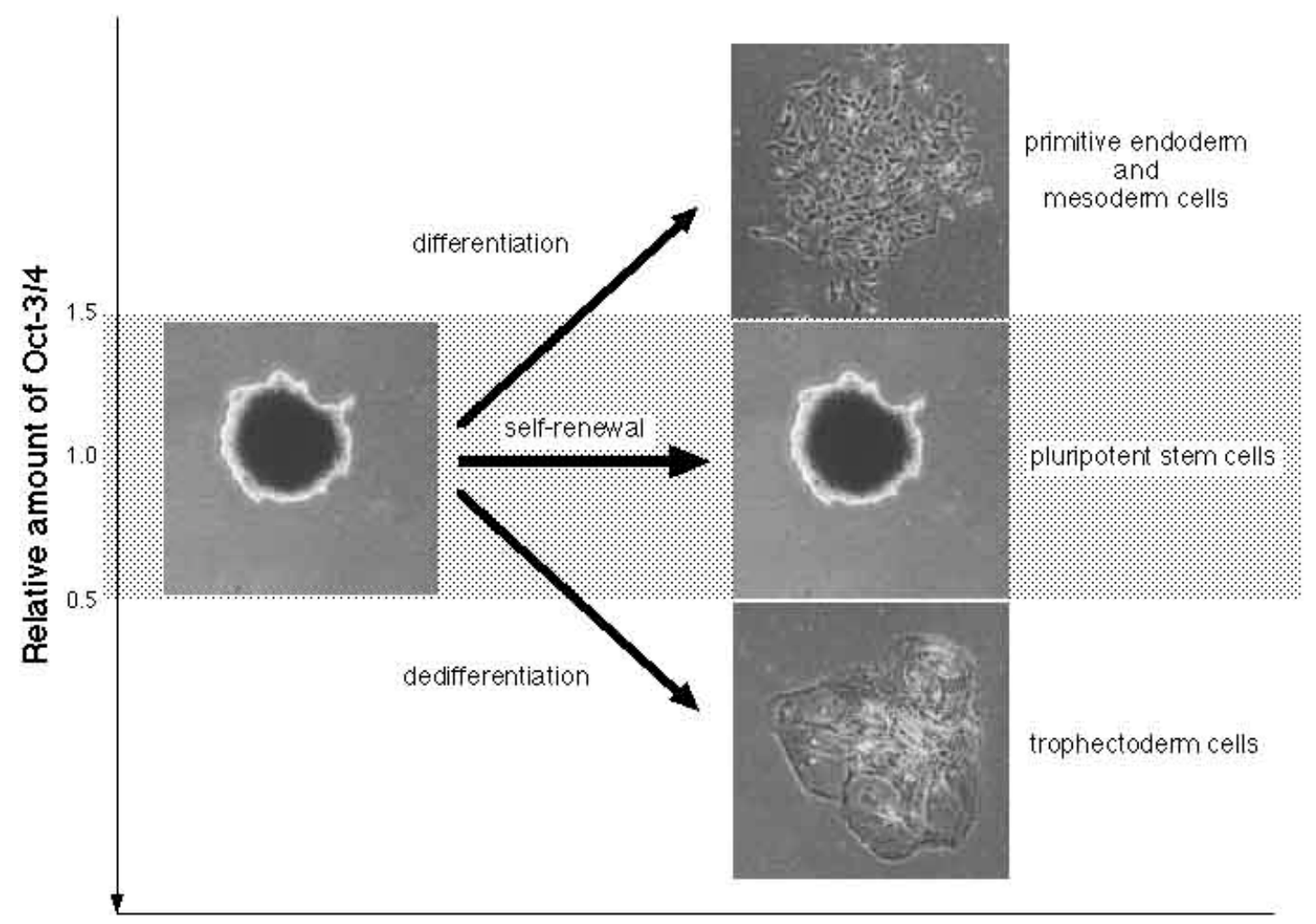

Fig. 2. Relationship between Oct-3/4 expression and stem cell fate. To maintain the undifferentiated phenotype, Oct-3/4 expression must remain within plus or minus $50 \%$ of normal diploid expression. If Oct-3/4 expression is increased beyond the upper threshold level, differentiation into primitive endoderm and mesoderm is triggered. If Oct-3/4 expression is decreased below the lower threshold level, stem cells are dedifferentiated into trophectoderm lineage.

Yuan et al., 1995; Okamoto et al., 1990). It was shown that Oct-3/4 can bind a variety of sequences including the consensus octamer motif (ATGCAAAT) and the AT-rich sequence (Saijoh et al., 1996; Okamoto et al., 1990), hence the high-affinity binding sites would be determined by association with appropriate co-factors which also have sequence-specific DNA-binding abilities. Oct-3/4 adopts various monomer configulations on DNA and can form homo- and heterodimers on the palindromic Oct factor recognition element and its derivatives (Tomilin et al., 2000; Botquin et al., 1998).

The genes encoding Fgf-4 (Yuan et al., 1995), the transcriptional co-factor Utf-1 (Nishimoto et al., 1999), the zinc-finger protein Zfp42/Rex-1 (Ben-Shushan et al., $1998)$ and the platelet-derived growth factor $\alpha$ receptor $(P D G F \alpha R)$ (Kraft et al., 1996) were identified as targets of Oct-3/4 by their stem cell-specific expression. Regulation of osteopontin (Opn) by Oct-3/4 was determined by immunoprecipitation of the first intron of $O p n$ from covalently-fixed chromatin of EC cells by Oct-3/4specific antibodies (Botquin et al., 1998). Saijoh et al. systematically isolated several candidates of target genes by their elegant cDNA subtraction screening method (Saijoh $e t$ al., 1996), and we confirmed Oct-3/4-dependent expression in ES cells for some of them, Otx-2, Lefty-1/Ebaf, uridine phosphorylase (Upp)/383 and Tera/226 (Niwa et al., 2000). All of these defined and putative target genes showed stem cell-specific expression in ES cells, but they exhibit differential expression pattern in pre- and early postimplantation embryos (Table I). Although all these genes express in the ICM of blastocyst, expressions of Lefty-1/Ebaf, Opn, Zfp42/Rex-1 and Upp/383 were not observed in PEC in egg cylinder stage embryos that possess pluripotency and express Oct-3/4. Oct-3/4 has been identified as a repressor on the expression of human chorionic gonadotropin $\beta$ subunit $(h C G \beta)$ in choriocarcinoma cells (Liu and Roberts, 1996), and our previous data suggested that Oct-3/4 repress directly or indirectly the caudal-related homeobox transcription factor $C d x$-2 and the basic helix-loop-helix transcription factor Hand-1 (also known as eHand or Hxt) (Niwa et al., 2000), both of which express in the trophectoderm lineage in the early stage embryos (Beck et al., 1995; Cross et al., 1995).

Little is known about the function of these target genes. $F g f-4$ is the best analyzed one, the function of which is essential for peri-implantation development (Feldman et al., 1995). However, it has been revealed that the function of Fgf-4 is not essential for stem cell renewal of ES cells and might be important as a paracrine growth factor for polar trophectoderm and primitive endoderm (Tanaka et al., 

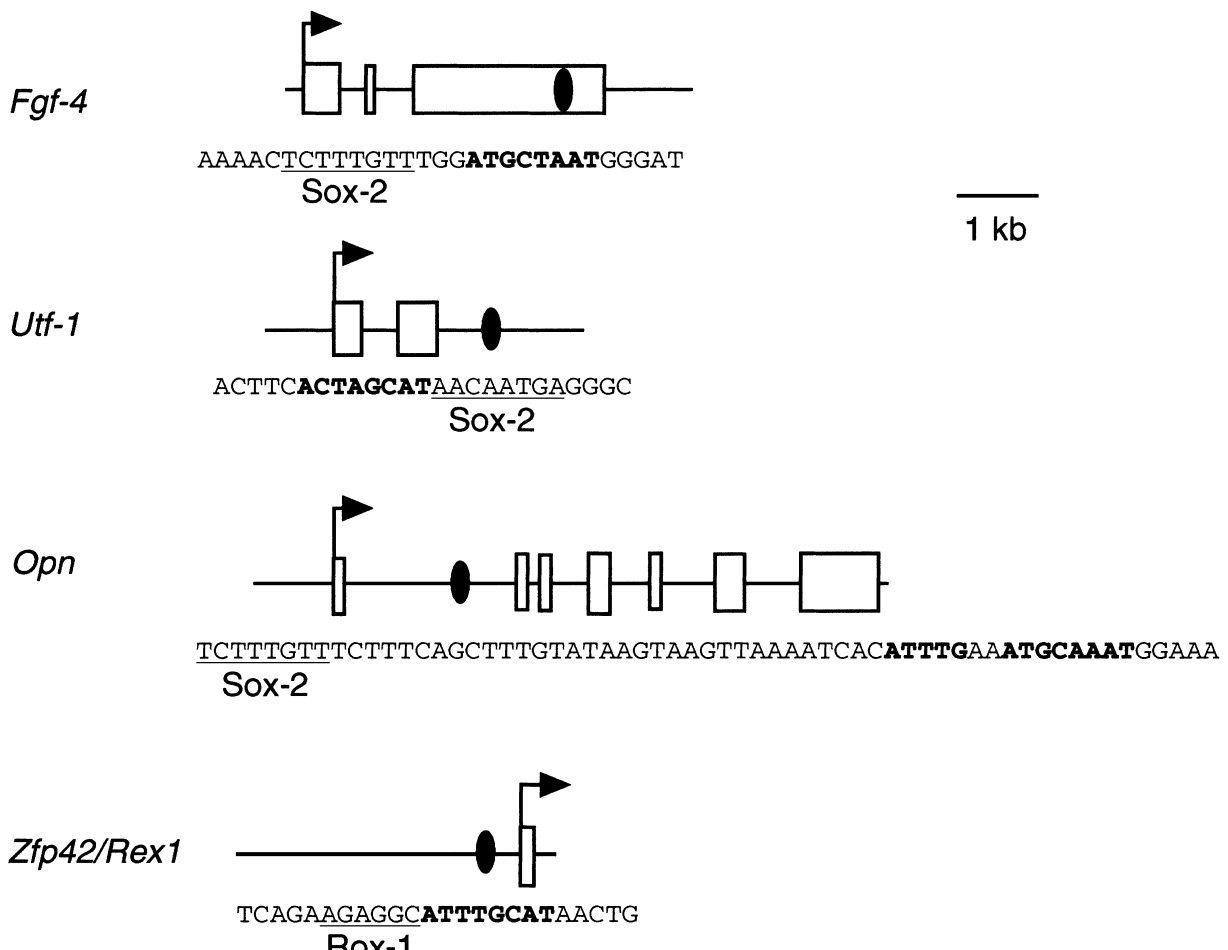

Rox-1
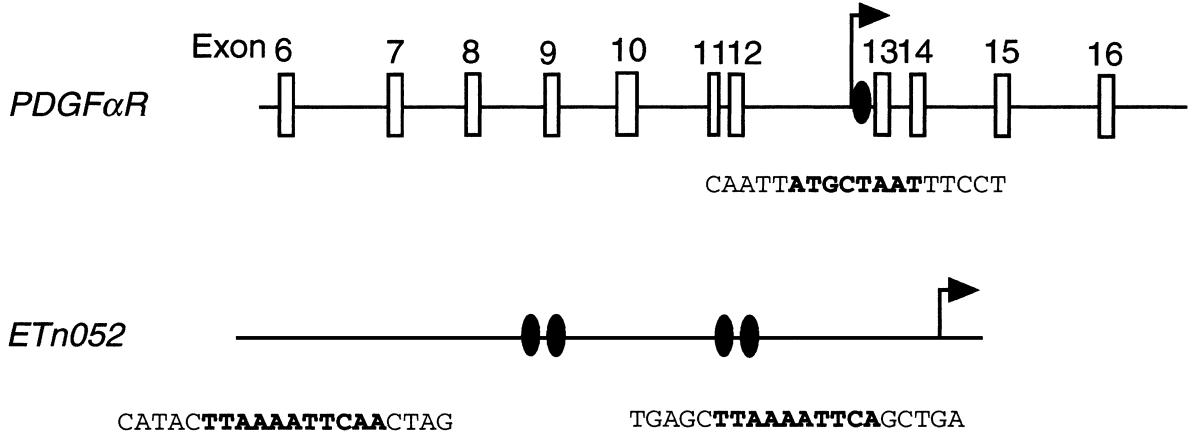

TACTAATTAGCATTATAA

TTACAATTTGCATTTAAA

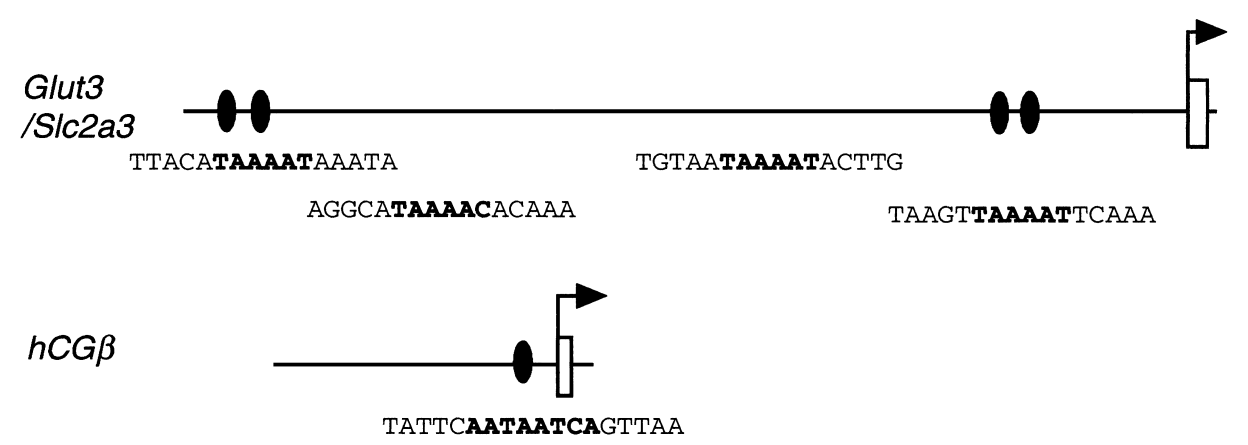

Fig. 3. Target genes of Oct-3/4. Position and sequence of the Oct-3/4 binding elements of Fgf-4 (Yuan et al., 1995), Utf1 (Okuda et al., 1998), Opn (Botquin et al., 1998), Zfp42/Rex-1 (Ben-Shushan et al., 1998), PDGF $\alpha$ R (Kraft et al., 1996), ETn052 (Okamoto et al., 1990), Slc2a3/Glut3 (Saijoh et al., 1996), and $h C G \beta$ (Liu and Roberts, 1996) are highlighted. Bold letters show the binding sequence of Oct-3/4, and the underlined letters indicate the binding site of co-factors. The task is to find the various positions of the binding sites in these target genes, which may correlate with different dependency of cofactors. 
Table I. EXPRESSION PATTERN OF OCT-3/4 TARGET GENES IN PLURIPOTENT CELLS

\begin{tabular}{|c|c|c|c|c|}
\hline \multicolumn{5}{|c|}{ embryos } \\
\hline Gene & ICM & PEC & $\mathrm{ES}^{\mathrm{m}}$ & squelching $^{\mathrm{m}}$ \\
\hline$F g f-4$ & $t^{\mathrm{a}}$ & $t^{\mathrm{a}}$ & + & - \\
\hline$U t f-1$ & $+^{\mathrm{b}}$ & $+^{\mathrm{b}}$ & $+^{\mathrm{n}}$ & $-^{\mathrm{n}}$ \\
\hline Tera/226 & $+^{\mathrm{c}}$ & $+^{\mathrm{d}}$ & + & + \\
\hline Lefty-1 & $+^{\mathrm{e}}$ & $-^{\mathrm{f}}$ & + & - \\
\hline$O t x-2$ & $+^{\mathrm{e}}$ & $t^{\mathrm{g}}$ & + & - \\
\hline Opn & $+^{\mathrm{h}}$ & $-^{\mathrm{h}}$ & $+^{\mathrm{h}}$ & nd \\
\hline Zfp42/Rex-1 & $+^{\mathrm{i}}$ & $-^{\mathrm{i}}$ & + & + \\
\hline Upp/383 & $++^{\mathrm{d}}$ & $-^{\mathrm{d}}$ & + & + \\
\hline Slc $2 a 3 / G l u t-3$ & $+^{\mathrm{d}}$ & $++^{\mathrm{d}}$ & + & - \\
\hline Sox -2 & $+^{\mathrm{e}}$ & $+^{\mathrm{j}}$ & + & \\
\hline ELA & $+^{\mathrm{k}, 1}$ & $-^{\mathrm{k}, 1}$ & $+^{\mathrm{o}}$ & \\
\hline
\end{tabular}

All genes except Sox-2 and ELA are candidates as Oct-3/4 targets. References for their expression in pluripotent cells are listed below; ${ }^{\mathrm{a}}(\mathrm{Rappolee}$ et al., 1994); ' (Okuda et al., 1998); ' hit to EST of blastocysts; ${ }^{\text {(Saijoh et }}$ al., 1996); ' Matsui, H. \& Niwa, H., unpublished; ${ }^{\mathrm{f}}$ (Meno et al., 1997); $\mathrm{g}$ (Simeone et al., 1993); ${ }^{\mathrm{h}}$ (Botquin et al., 1998); ${ }^{\mathrm{i}}$ (Rogers et al., 1991); j(Collignon et al., 1996); '(Suemori et al., 1988); '(Dooley et al., 1989); ${ }^{\mathrm{m}}$ (Niwa et al., 2000); ${ }^{\mathrm{n} N i w a ~ H ., ~ u n p u b l i s h e d ; ~}{ }^{\circ}($ Suemori et al., 1988).

1998; Wilder et al., 1997). Functional analysis of Otx-2 (Matsuo et al., 1995), Lefty-1/Ebaf (Meno et al., 1998) and Opn (Hynes, 1996) using knckout mice revealed that functions of these genes were not essential to establish the pluripotent cell population in preimplantation-stage embryos which affected in Oct-3/4 knockout embryos. In contrast, targeted inactivation of $C d x-2$ resulted in embryonic lethality between $3.5-5.5$ day postcoitum (Chawengsaksophak et al., 1997) and Hand-1 mutant embryos exhibit defect in differentiation of secondary giant cells in placenta (Firulli et al., 1998; Riley et al., 1998), indicating the important role of these genes in placental development.

\section{Co-factors}

It is known that POU family transcription factors can act as both transcriptional activators and repressors by cooperating with various co-factors (Xu et al., 1998; Gstaiger et al., 1995; Zwilling et al., 1995; Lai et al., 1992), and several different co-factors of Oct-3/4 have been reported. The first co-factor of Oct-3/4 identified was the adenovirus E1A (Schöler et al., 1991), which was regarded as a substitute of the so-called E1A-like activity (ELA) observed in undifferentiated cells ( $\mathrm{La}$ Thangue and Rigby, 1987). For activation of the artificial promoter in heterologous cells, E1A served as a bridging factor between Oct-3/4 and the basic transcription machinery. The second one was the Sry-related factor Sox-2, which was initially identified as a co-factor to activate $F g f-4$ enhancer (Yuan $e t$ $a l ., 1995)$ and then found to activate the Utf-l enhancer (Nishimoto et al., 1999). In contrast, it was reported that Sox-2 prevents activation of the Opn enhancer by homodimer of Oct-3/4 (Botquin et al., 1998). In the case of the Zfp42/Rex-1 promoter, the unidentified factor Rox-1 was hypothesized as a new co-factor of Oct-3/4 (Ben-Shushan et al., 1998), and screening of the phage display library revealed interaction of several factors with Oct-3/4, which included HMG-1 (Butteroni et al., 2000). It was known that the allosteric effect results in the recruitment of a corepressor complex on the POU factor Pit-1 which usually interacts with a coactivator complex (Scully et al., 2000), so a similar effect might provide the repressor function on Oct-3/4.

One interesting observation in the cooperation between Oct-3/4 and co-factors was the squelching phenomenon (Schöler et al., 1991). In transactivation of the artificial promoter element by Oct-3/4 and E1A, the quantitative balance between these factors is important for proper activation by a ternary complex that consists of Oct-3/4, E1A and the basal transcription machinery. Excess amounts of Oct-3/4 or E1A prevent formation of active complex by occupation of binding site or surface saturation, respectively, resulting in prevention of activating the target promoter. A similar phenomenon was observed in the activation of the Zfp42/Rex-1 promoter (Ben-Shushan et al., 1998), which was repressed by excess amounts of Oct-3/4 in EC cells, but not in the $F g f-4$ and $U t f-1$ enhancers activated by Oct-3/4 and Sox-2 (Nishimoto et al., 1999; Yuan et al., 1995).

Another point of interest is that these co-factors of Oct-3/4 exhibit different expression patterns in pluripotent cells. Sox-2 expresses in both ICM and PEC (Botquin et al., 1998)(Collignon et al., 1996), but ELA was observed only in ICM (Dooley et al., 1989; Suemori et al., 1988) (Table I). Therefore, the differential expression of target genes might be due to their different dependency of co-factors. An alternative explanation is that the expression of these target genes is differentially regulated by factors other than Oct-3/4, which mostly happens on the two separate enhancers of Oct-3/4 itself (Yeom et al., 1996) (see below).

\section{Functional domains}

Oct-3/4 consists of a bipartite DNA-binding POU domain and both amino-terminal and carboxy-terminal transactivation domains (Okamoto et al., 1990; Rosner et al., 1990; Schöler et al., 1990a). The functional difference between these separate transactivation domains was reported (Ambrosetti et al., 2000; Brehm et al., 1997; Viganó and Staudt, 1996; Imagawa et al., 1991), but our recent finding clearly indicated that they share redundant functions on ES self-renewal, and that the combination of one of them with the proper POU domain is sufficient to substitute for the function of Oct-3/4 in ES cells (Niwa et al., submitted for 
publication). Interestingly, the DNA-binding ability of Oct-3/4 is essential to maintain ES cell phenotype but not to induce differentiation by overproduction, suggesting that the titration out of relevant partner(s) (Schöler et al., 1991) is achieved by protein-protein interactions that are independent of DNA-binding (Niwa et al., submitted for publication).

\section{Model for molecular mechanism governs ES cell phenotype}

A model for Oct-3/4 and Stat3 cooperative function is shown in Fig. 4 as proposed in our previous report (Niwa et al., 2000). The categorization of Oct-3/4 target genes into three groups A to $\mathrm{C}$ is based on (1) the function of Oct-3/4 on these targets (activation or repression) and (2) the expression pattern in ES cells with excess amounts of Oct-3/4 (repressed by squelching or not). As shown above, up-regulation of Oct-3/4 results in differentiation to primitive endoderm and mesoderm, which is different from the phenotype generated by its down-regulation. The squelching phenomenon can give the explanation that excess amounts of Oct-3/4 result in its loss-of-function on activation of target genes, but repression by overexpression of Oct-3/4 occurs only in a part of target genes such as Zfp42/Rex-1 and Upp/383. Therefore, a hypothesis was introduced in a key position of this model, in which the target genes activated by Oct-3/4 can be divided into two groups, one is repressed by squelching mechanism and the other is not, and the difference between them is based on their different co-factor dependency. This hypothesis can be supported by the correlation between differential expression patterns of co-factors and target genes in pluripotent cells (Table I) and the different co-factor dependencies of known target genes. Indeed, the co-factor Sox-2 and two Sox-2dependent Oct-3/4 target $F g f-4$ and $U t f-1$ co-express in both ICM and PEC (Table I), and neither Fgf-4 norUtf- 1 was repressed by overproduction of Oct-3/4 in ES cells (Niwa et al., 2000, and unpublished result), as there is no evidence suggesting that the squelching occurs between Oct-3/4 and
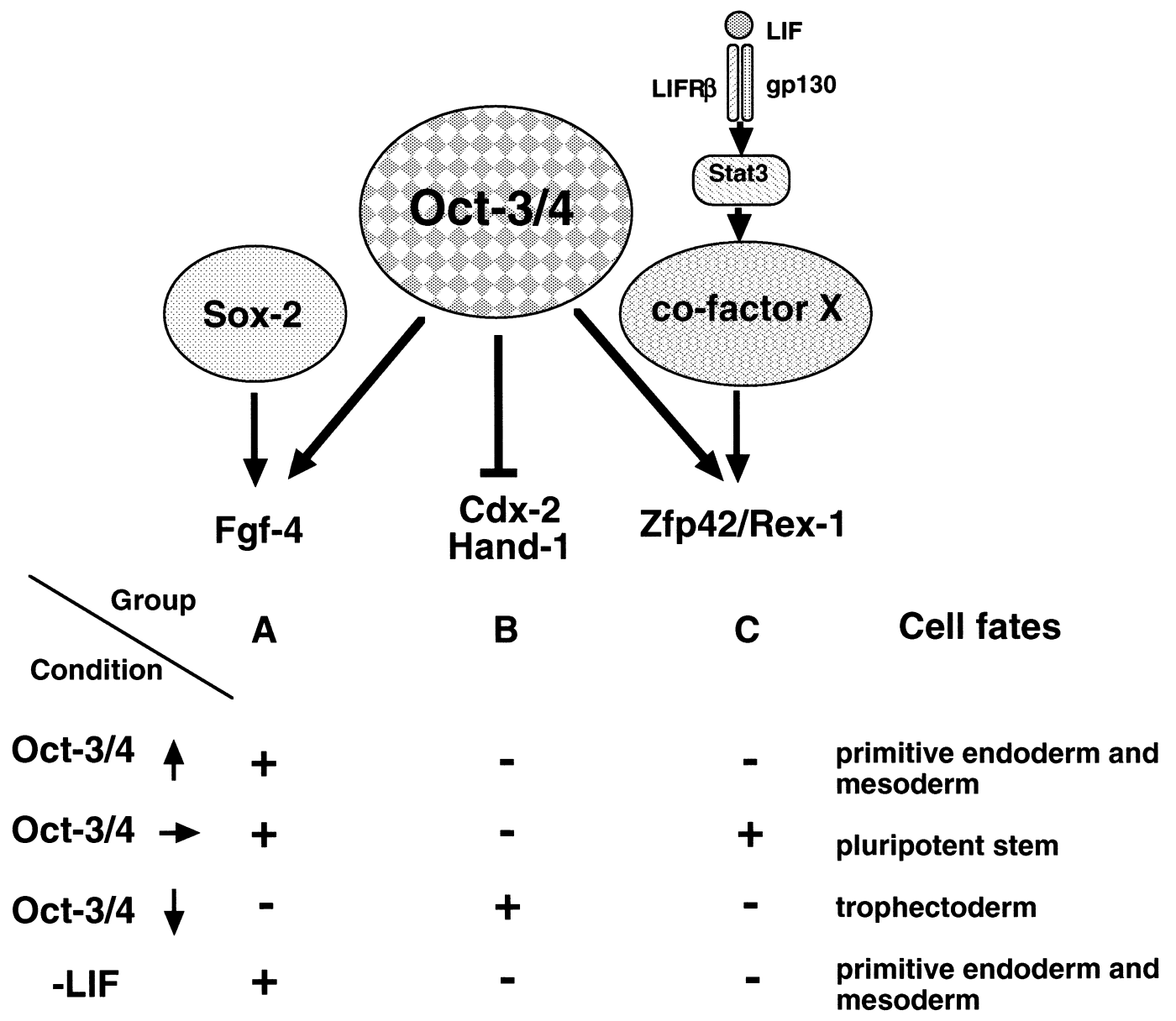

Fig. 4. Model for Oct-3/4 and Stat 3 co-operative function. Putative and defined Oct-3/4 target genes are divided into three groups and the typical members of genes in each group are shown. By introduction of two hypotheses in the model, we can explain all phenomenon observed by the change of Oct-3/4 expression and/or withdrawal of LIF. See the text for details. 
Sox-2. In contrast, the two target genes repressed by overexpression of Oct-3/4, Zfp42/Rex-1 and Upp/383, express in ICM but not in PEC, and the putative co-factor ELA exhibits the same expression pattern as these genes (Table I), which substitute E1A to mediate the squelching phenomenon. In Fig. 4, Sox-2 represents a co-factor that does not mediate squelching, while co-factor $\mathrm{X}$ represents a co-factor that mediates squelching. Group A target genes are activated by Oct-3/4 and the Sox-2-class co-factors and not repressed by squelching, while group $\mathrm{B}$ ones are repressed by Oct-3/4, and group $\mathrm{C}$ ones are activated by Oct-3/4 and co-factor $\mathrm{X}$ and repressed by squelching. When the Oct-3/4 expression is maintained within the appropriate level, the expression pattern of these groups $[\mathrm{A}, \mathrm{B}, \mathrm{C}]$ is [ON,OFF,ON], resulting in stem cell renewal. By downregulation of Oct-3/4, the expression pattern of these groups is inverted to [OFF, ON,OFF], resulting in differentiation to trophectoderm. Since the genes involved in placental development belongs to group $\mathrm{B}$, it would seem that a component of Oct-3/4 functions as a gatekeeper that prevents differentiation into the trophectoderm lineage and thereby locks pluripotent capacity. Up-regulation of Oct-3/4 results in shutting off group $\mathrm{C}$ and provides the expression pattern $[\mathrm{ON}, \mathrm{OFF}, \mathrm{OFF}]$ for the expression of the groups $[\mathrm{A}, \mathrm{B}, \mathrm{C}]$, which is different from the pattern shown above and results in differentiation to primitive endoderm and mesoderm. Such choice of cell fate might be achieved by down-regulation of group $\mathrm{C}$, which may be required for maintaining stem cell renewal, while keeping repressed the group B genes involved in commitment to trophectoderm lineage. A similar situation obtains by repression of cofactor X, and it may also happen in PEC as observed in ELA (Dooley et al., 1989; Suemori et al., 1988) to allow their differentiation to embryonic tissues via gastrulation.

To explain the relationship between the LIF/Stat3 pathway and Oct-3/4, a second hypothesis is incorporated in this model, in which Stat 3 activates the expression of cofactor $\mathrm{X}$. This hypothesis is based on the evidence that overexpression of Oct-3/4 and withdrawal of LIF induce a similar differentiation and allows explanation of this result because both of these events give the same expression pattern $[\mathrm{ON}, \mathrm{OFF}, \mathrm{OFF}]$ of the groups $[\mathrm{A}, \mathrm{B}, \mathrm{C}]$. It also fits the observation that maintenance of Oct-3/4 expression is not sufficient to keep stem cell phenotype in the absence of LIF (Niwa et al., 2000).

To confirm this model, it is necessary to prove these two hypotheses. The common component of them is co-factor $\mathrm{X}$, which may correspond to the hypothetical factor Rox-1 or the unidentified ELA. For this purpose, the systematic identification of the proteins that interact with Oct-3/4 is essential in future.

\section{Regulation of Oct-3/4 expression}

If the change of Oct-3/4 expression level is a primary event to determine cell fates in preimplantation development, how is it achieved? In ES cells, the transcription level of Oct-3/4 should be kept in the narrow range to maintain pluripotent cell phenotype. For such tight regulation of transcription, a negative feedback mechanism should be present in pluripotent cells expressing Oct-3/4 Indeed, in the model system in Escherichia coli, the presence of a simple negative feedback loop dramatically keeps the expression level within the narrow range, within $5 \%$ of the average level (Becskei and Serrano, 2000). However, there is no experimental evidence which suggests the presence of such a simple negative feedback loop in the regulation of Oct-3/4 expression. Analysis of the regulatory element of Oct-3/4 revealed that there are two separate enhancer elements upstream the Oct-3/4 promoter, a distal enhancer (DE) and a proximal enhancer (PE) (Yeom et al., 1996). DE is active in ICM and PGC but not in PEC, whereas PE is active only in PEC. Among the pluripotent cell lines, DE is active in ES and embryonic germ (EG) cells whereas PE is active in EC cells. Only PE has been analyzed in detail and it was revealed that transcription factors that belong to the nuclear receptor superfamily bind to the core element of PE (Sylvester and Schöler, 1994). COUP-TFs act as a negative regulator on this element (BenShushan et al., 1995) and GCNF exhibits a pattern of expression that suggests it could be involved in regulating the activity of Oct-3/4 promoter (Chen et al., 1994), so they can be regarded as candidate components of a negative feedback loop.

\section{Evolutional location of LIF/Stat3 and Oct-3/4}

In mouse ES cells, both the LIF/Stat3 pathway and the transcription factor Oct-3/4 have a pivotal role to keep cellular pluripotency. Such an important mechanism tends to be evolutionally conserved, but there are lines of evidence to prevent generalization of this model to other species. For example, all mouse ES cell lines have dependency to LIF, although there are variations in degree; for instance, the recently established rhesus and human ES cells do not exhibit clear dependency to LIF (Thomson et al., 1998; Thomson et al., 1995). Medaka ES cell lines also undergo self-renewal without LIF (Hong et al., 1996), but ES cell lines of chicken (Pain et al., 1996), rat (Lannaccone et al., 1994), and EG cell lines of mouse (Matsui et al., 1992) and human (Shamblott et al., 1998) undergo stem cell renewal in LIF-dependent manner. Interestingly, most of mouse EC cell lines can grow up without LIF and overexpression of Stat3F cannot prevent it (Niwa et al., 1998), which rules out the hypothesis that an alternative pathway activates Stat3 in these EC cells to keep the expression of co-factor $\mathrm{X}$ without LIF. Therefore, it is still unclear how the pluripotency is maintained in LIFindependent ES and EC cell lines. One possible explanation is the variation in balance between the dependency to the 
LIF/Stat3 pathway and the ESRF pathway. To test this hypothesis, identification of ESRF should be done first.

Oct-3/4 function looks like well conserved among the mammals. The human ES cells express Oct-3/4 in stem cellspecific manner (Reubinoff et al., 2000), and expression of Oct-3/4 is tightly regulated in human ICM cells whereas it is repressed in trophectoderm (Hansis et al., 2000). In domestic animals, Oct-3/4 expression can be detected in both ICM and trophectoderm (Kirchhof et al., 2000; van Eijk et al., 1999), but the decrease of Oct-3/4 expression to induce differentiation, which is only a $50 \%$ reduction in mouse ES cells (Niwa et al., 2000), may happen in the trophectoderm although the precise estimation of expression level has not been done. Overexpression of Oct-3/4 in mouse EC cells can induce differentiation (Niwa, H., unpublished results), indicating the same function in LIFindependent pluripotent cells as in mouse ES cells. However, to date, Oct-3/4 homologue has been found only in mammals such as marsupial brushtail possum (Frankenberg et al., 2001), mouse (Okamoto et al., 1990; Rosner et al., 1990; Schöler et al., 1990a), bovine (van Eijk et al., 1999) and human (Takeda et al., 1992). Oct-3/4 belongs to the class V of the POU family (Rosenfeld, 1991), and the members of this class were identified in Zebrafish and Xenopus but not in Caenorhabditis elegans and Drosophila melanogaster genomes, and systematic search of chicken genome failed to identify any homologous gene (Soodeen-Karamath and Verrinder Gibbins, 2001). These data indicate that the class V POU factor is evolutionally new in this family because members in the other class can be observed in Caenorhabditis elegans and Drosophila melanogaster (reviewed by Ryan and Rosenfeld, 1997), and the conserved mechanism to keep pluripotency other than Oct-3/4 should be present because ES cell lines were established from the species in which Oct-3/4 homolog have not been identified such as chicken (SoodeenKaramath and Verrinder Gibbins, 2001; Pain et al., 1996). Since the precise level of Oct-3/4 governs three distinct fates of mouse ES cells, it can be regarded as a switch to separate the placental and embryonic lineages. Therefore, this would lead us to speculate that Oct-3/4 is an optional switch to generate the placenta in the evolution of mammals, in which the evolutionally conserved mechanism to keep pluripotency is under the control of Oct-3/4 as the group $\mathrm{C}$ target genes.

\section{References}

Ambrosetti, D.-C., Schöler, H.R., Dailey, L., and Basilico, C. 2000. Modulation of the activity of multiple transcriptional activation domains by the DNA binding domains mediates the synergistic action of Sox 2 and Oct-3 on the fibroblast growth factor-4 enhancer. J. Biol. Chem., 275: 23387-23397.

Beck, F., Erier, T., Russell, A., and James, R. 1995. Expression of Cdx-2 in the mouse embryo and placenta: possible role in patterning of the extra-embryonic membranes. Dev. Dyn., 204: 219-227.
Becskei, A. and Serrano, L. 2000. Engineering stability in gene networks by autoregulation. Nature, 405: 590-593.

Ben-Shushan, E., Sharir, H., Pikarsky, E., and Bergman, Y. 1995. A dynamic balance between ARP-1/COUP-TFII, EAR-3/COUP-TFI, and retinoic acid receptor:retinoid $\mathrm{X}$ receptor heterodimers regulates Oct-3/4 expression in embryonal carcinoma cells. Mol. Cell. Biol., 15: 10341048.

Ben-Shushan, E., Thompson, J.R., Gudas, L.J., and Bergman, Y. 1998. Rex-1, a gene encoding a transcription factor expressed in the early embryo, is regulated via Oct-3/4 and Oct- 6 binding to an octamer site and a novel protein, Rox-1, binding to an adjacent site. Mol. Cell Biol., 18: $1866-1878$.

Botquin, V., Hess, H., Fuhrman, G., Anastassiadis, C., Gross, M.K., Vriend, G., and Schöler, H.R. 1998. New POU dimer configuration mediates antagonistic control of an osteopontin preimplantation enhancer by Oct-4 and Sox-2. Genes \& Dev., 12: 2073-2090.

Brehm, A., Ohbo, K., and Schöler, H. 1997. The carboxy-terminal transactivation domain of Oct-4 acquires cell specificity through the POU domain. Mol. Cell. Biol., 17: 154-162.

Burdon, T., Stracey, C., Chambers, I., Nichols, J., and Smith, A. 1999a. Suppression of SHP-2 and ERK signalling promotes self-renewal of mouse embryonic stem cells. Dev. Biol., 210: 30-43.

Burdon, T., Chambers, I., Stracey, C., Niwa, H., and Smith, A. 1999b. Signaling mechanisms regulating self-renewal and differentiation of pluripotent embryonic stem cells. Cells Tissues Organs, 165: 131-143.

Butteroni, C., De Felici, M., Schöler, H.R., and Pesce, M. 2000. Phage display screening reveals an association between germline-specific transcription factor Oct-4 and multiple cellular proteins. J. Mol. Biol., 304: 529-540.

Chawengsaksophak, K., James, R., Hammond, V.E., Köntgen, F., and Beck, F. 1997. Homeosis and intestinal tumours in Cdx2 mutant mice. Nature, 386: 84-87.

Chen, F., Cooney, A.J., Wang, Y., Law, S.W., and O'Malley, B.W. 1994. Cloning of a novel orphan receptor (GCNF) expressed during germ cell development. Mol. Endocrinol., 8: 1434-1444.

Collignon, J., Sockanathan, S., Hacker, A., Cohen-Tannoudji, M., Norris, D., Rastan, S., Stevanovic, M., Goodfellow, P.N., and Lovell-Badge, R. 1996. A comparison of the properties of Sox-3 with Sry and two related genes, Sox-1 and Sox-2. Development, 122: 509-520.

Cross, J.C., Flannery, M.L., Blanar, M.A., Steingrimsson, E., Jenkins, N.A., Copeland, N.G., Rutter, W.J., and Werb, Z. 1995. Hxt encodes a basic helix-loop-helix transcription factor that regulates trophoblast cell development. Development, 121: 2513-2523.

Dani, C., Chambers, I., Johnstone, S., Robertson, M., Ebrahimi, B., Saito, M., Taga, T., Li, M., Burdon, T., Nichols, J., and Smith, A. 1998. Paracrine induction of stem cell renewal by LIF-deficient cells: a new ES cell regulatory pathway. Dev. Biol., 203: 149-162.

Dooley, T.P., Miranda, M., Jones, N.C., and DePamphilis, M.L. 1989. Transactivation of the adenovirus EIIa promoter in the absence of adenovirus E1A protein is restricted to mouse oocytes and preimplantation embryos. Development, 107: 945-956.

Feldman, B., Poueymirou, W., Papaiannou, V.E., DeChiara, T.M., and Goldfarb, M. 1995. Requirement of FGF-4 for postimplantaion mouse development. Science, 267: 246-249.

Firulli, A.B., McFadden, D.G., Lin, Q., Srivastava, D., and Olson, E.N. 1998. Heart and extra-embryonic mesodermal defects in mouse embryos lacking the bHLH transcription factor Hand1. Nat. Genet., 18: 266-270.

Frankenberg, S., Tisdall, D., and Selwood, L. 2001. Identification of a homologue of POU5F1 (OCT3/4) in a marsupial, the brushtail possum. Mol. Reprod. Dev., 58: 255-261.

Gearing, P.D., Gough, N.M., King, J.A., Hilton, D.J., Nicola, N.A., SImpson, R.J., Nice, E.C., Kelso, A., and Metcalf, D. 1987. Molecular 
cloning and expression of cDNA encoding a murine myeloid leukemia inhibitory factor (LIF). EMBO J., 6: 3995-4002.

Gstaiger, M., Knoepfel, L., Georgiev, O., Schaffner, W., and Hovens, C.M. 1995. A B-cell coactivator of octamer-binding transcription factors. Nature, 373: 360-362.

Hansis, C., Grifo, J.A., and Krey, L.C. 2000. Oct-4 expression in inner cell mass and trophectoderm of human blastocysts. Mol. Hum. Reprod., 6: 999-1004.

Hirano, T., Nakajima, K., and Hibi, M. 1997. Signaling mechanisms through gp130: A model of the cytokine system. Cytokine Growth Factor Rev., 8: 241-252.

Hirano, T., Ishihara, K., and Hibi, M. 2000. Roles of STAT3 in mediating the cell growth, differentiation and survival signals relayed through the IL-6 family of cytokine receptors. Oncogene, 19: 2548-2556.

Hong, Y., Winkler, C., and Schartl, M. 1996. Pluripotency and differentiation of embryonic stem cell lines from the medakafish (Oryzias latipes). Mech. Dev., 60: 33-44.

Hynes, R.O. 1996. Targeted mutations in cell adhesion genes: What have we learned from them? Dev. Biol., 180: 402-412.

Imagawa, M., Miyamoto, A., Shirakawa, M., Hamada, H., and Muramatsu, M. 1991. Stringent integrity requirements for both trans-activation and DNA-binding in a trans-activator, Oct3. Nucleic Acids Res., 19: 45034508 .

Kirchhof, N., Carnwath, J.W., Lemme, E., Anastassiadis, K., Schöler, H.R., and Niemann, H. 2000. Expression pattern of Oct-4 in preimplantation embryos of different species. Biol. Reprod., 63: 1698-1705.

Kraft, H.J., Mosselman, S., Smits, H.A., Hohemstein, P., Piek, E., Chen, Q., Artzt, K., and van Zoelen, E.J.J. 1996. Oct-4 regulates alternative platelet-derived growth factor $\alpha$ receptor gene promoter in human embryonal carcinoma cells. J. Biol. Chem., 271: 12873-12878.

La Thangue, N.B. and Rigby, P.W.J. 1987. An adenovirus E1A-like transcription factor is regulated during the differentiation of murine embryonal carcinoma stem cells. Cell, 49: 507-513.

Lai, J.-S., Cleary, M.A., and Herr, W. 1992. A single amino acid exchange transfers VP16-induced positive control from the Oct-1 to the Oct-2 homeodomain. Genes \& Dev., 6: 2058-2065.

Lannaccone, P.M., Taborn, G.U., Carton, R.L., Caplice, M.D., and Brenin, D.R. 1994. Pluripotent embryonic stem cells from the rat are capable of producing chimeras. Dev. Biol., 163: 288-292.

Li, M., Sendtner, M., and Smith, A. 1995. Essential function of LIF receptor in motor neurons. Nature, 378: 724-727.

Liu, L. and Roberts, R.M. 1996. Silencing of the gene for the $\beta$-subunit of human chorionic gonadotropin by the embryonic transcription factor Oct-3/4. J. Biol. Chem., 271: 16683-16689.

Matsuda, T., Nakamura, T., Nakao, K., Arai, T., Katsuki, M., Heike, T., and Yokota, T. 1999. STAT3 activation is sufficient to maintain an undifferentiated state of mouse embryonic stem cells. EMBO J., 18: 4261-4269.

Matsui, Y., Zsebo, K., and Hogan, B.L. 1992. Deviation of pluripotential embryonic stem cells from murine primodial germ cells in culture. Cell, 70: $841-847$.

Matsuo, I., Kuratani, S., Kimura, C., Takeda, N., and Aizawa, S. 1995. Mouse Otx-2 functions in the formation and patterning of rostal head. Genes \& Dev., 9: 2646-2658.

Meno, C., Ito, Y., Saijoh, Y., Matsuda, Y., Tashiro, K., Kuhara, S., and Hamada, H. 1997. Two closely-related left-right asymmetrically expressed genes, lefty- 1 and lefty-2: their distinct expression domains, chromosomal linkage and direct neuralizing activity in Xenopus embryos. Genes to Cells, 2: 513-524.

Meno, C., Shimono, A., Saijoh, Y., Yashiro, K., Mochida, K., Ohishi, S., Noji, S., Kondoh, H., and Hamada, H. 1998. lefty-1 is required for leftright determination as a regulator of lefty- 2 and nodal. Cell, 94: 287297.
Minami, M., Inoue, M., Wei, S., Takeda, K., MAtsumoto, M., Kishimoto, T., and Akira, S. 1996. STAT3 activation is a critical step in gp130-mediated terminal differentiation and growth arrest of a myeloid leukemia cell line. Proc. Natl. Acad. Sci. USA, 93: 3963-3966.

Nakajima, K., Yamanaka, Y., Nakae, K., Kojima, H., Ichiba, M., Kiuchi, N., Kitaoka, T., Fukada, T., Hibi, M., and Hirano, T. 1996. A central role for Stat3 in IL-6-induced regulation of growth and differentiation in M1 leukemia cells. EMBO J., 15: 3651-3658.

Nichols, J., Evans, E.P., and Smith, A.G. 1990. Establishment of germ-line competent embryonic stem (ES) cells using differentiation inhibiting activity. Development, 110: 1341-1348.

Nichols, J., Chambers, I., and Smith, A.G. 1994. Deviation of germline competent embryonic stem cells with combination of interleukin-6 and soluble interleukin-6 receptor. Exp. Cell Res., 215: 237-239.

Nichols, J., Zevnik, B., Anastassiadis, K., Niwa, H., Klewe-Nebenius, D., Chambers, I., Schöler, H., and Smith, A. 1998. Formation of pluripotent stem cells in the mammalian embryo depends on the POU transcription factor Oct4. Cell, 95: 379-391.

Nishimoto, M., Fukushima, A., Okuda, A., and Muramatsu, M. 1999. The gene for the embryonic stem cell coactivator UTF1 carries a regulatory element which selectively interacts with a complex composed of Oct-3/4 and Sox-2. Mol. Cell. Biol., 19: 5453-5465.

Niwa, H., Burdon, T., Chambers, I., and Smith, A. 1998. Self-renewal of pluripotent embryonic stem cells is mediated via activation of STAT3. Genes \& Dev., 12: 2048-2060.

Niwa, H., Miyazaki, J.-I., and Smith, A.G. 2000. Quantitative expression of Oct-3/4 defines differentiation, dedifferentiation or self-renewal of ES cells. Nat. Genet., 24: 372-376.

Okamoto, K., Okazawa, H., Okuda, A., Sakai, M., Muramatsu, M., and Hamada, H. 1990. A novel octamer binding transcriptional factor is differentially expressed in mouse embryonic cells. Cell, 60: 461-472.

Okuda, A., Fukushima, A., Nishimoto, M., Orimo, A., Yamagishi, T., Nabeshima, Y., Kuro-o, M., Nameshima, Y.-I., Boon, K., Keaveney, M., Stunnenberg, H.G., and Muramatsu, M. 1998. UTF-1, a novel transcriptional coactivator expressed in pluripotent embryonic stem cells and extra-embryonic cells. EMBO J., 17: 2019-2032.

Pain, B., Clark, M.E., Shen, M., Nakazawa, H., Sakurai, M., Samarut, J., and Etches, R.J. 1996. Long-term in vitro culture and characterization of avian embryonic stem cells with multiple morphogenetic potentialities. Development, 122: 2339-2348.

Palmieri, S.L., Peter, W., Hess, H., and Schöler, H.R. 1994. Oct-4 transcription factor is differentially expressed in the mouse embryo during establishment of the first two extraembryonic cell lineage involved in implantation. Dev. Biol., 166: 259-267.

Pesce, M., Gross, M.K., and Schöler, H.R. 1998a. In line with our ancestors: Oct-4 and the mammalian germ. BioEssays, 20: 722-732.

Pesce, M., Wang, X., Wolgemuth, D.J., and Scöler, H. 1998b. Differential expression of the Oct-4 transcription factor during mouse germ cell differentiation. Mech. Dev., 71: 89-98.

Pesce, M., Anastassiadis, K., and Schöler, H.R. 1999. Oct-4: lessons of totipotency from embryonic stem cells. Cells Tissues Organs, 165: 144152.

Qu, C.-K. and Feng, G.-S. 1998. Shp-2 has a positive regulatory role in ES cell differentiation and proliferation. Oncogene, 17: 433-439.

Rappolee, D.A., Basilico, C., Patel, Y., and Werb, Z. 1994. Expression and function of FGF-4 in peri-implantation development in the mouse embryo. Development, 120: 2259-2269.

Raz, R., Lee, C.-K., Cannizzaro, L.A., D'Eustachio, P., and Levy, D.E. 1999. Essential role of STAT3 for embryonic stem cell pluripotency. Proc. Natl. Acad. Sci. USA, 96: 2846-2851.

Reubinoff, B.E., Pera, M.F., Fong, C.-Y., Trounson, A., and Bongso, A. 2000. Embryonic stem cell lines from human blastocysts: somatic differentiation in vitro. Nat. Biotech., 18: 399-404. 
Riley, P., Anson-Cartwright, L., and Cross, J.C. 1998. The Hand1 bHLH transcription factor is essential for placental and cardiac morphogenesis. Nat. Genet., 18: 271-275.

Rogers, M.B., Hosler, B.A., and Gudas, L.J. 1991. Specific expression of a retinoic acid-regulated, zinc-finger gene, Rex-1, in preimplantation embryos, trophoblast and spermatocytes. Development, 113: 815-824.

Rosenfeld, M.G. 1991. POU-domain transcription factors: pou-er-ful developmental regulators. Genes \& Dev., 5: 897-907.

Rosner, M.H., Vigano, M.A., Ozato, K., Timmons, P.M., Poirier, F., Rigby, P.W.J., and Staudt, L.M. 1990. A POU-domain transcription factor in early stem cells and germ cells of the mammalian embryo. Nature, 345: 686-692.

Ryan, A.K. and Rosenfeld, M.G. 1997. POU domain family values: flexibility, partnerships, and developmental codes. Genes Dev., 11: 12071225.

Saijoh, Y., Fukii, H., Meno, C., Sato, M., Hirota, Y., Nagamatsu, S., Ikeda, M., and Hamada, H. 1996. Identification of putative downstream genes of Oct-3, a pluripotent cell-specific transcription factor. Genes Cells, 1: 239-252.

Saxton, T.M., Henkemeyer, M., Gasca, S., Shen, R., Rossi, D.J., Shalaby, F., Feng, G.-S., and Pawson, T. 1997. Abnormal mesoderm patterning in mouse embryos mutant for the SH2 tyrosine phosphatase SHP-2. EMBO J., 16: 2352-2364.

Schöler, H.R., Ruppert, S., Suzuki, N., Chowdhury, K., and Gruss, P. 1990a. New type of POU domain in germ line-specific protein Oct-4. Nature, 344: 435-439.

Schöler, H.R., Dressler, G.R., Baling, R., Rohdewohld, H., and Gruss, P. 1990b. Oct-4: a germline-specific transcription factor mapping to the mouse t-complex. EMBO J., 9: 2185-2195.

Schöler, H.R., Ciesiolka, T., and Gruss, P. 1991. A nexus between Oct-4 and E1A: implications for gene regulation in embryonic stem cells. Cell, 66: 291-304.

Scully, K.M., Jacobson, E.M., Jepsen, K., Lunyak, V., Viadiu, H., Carriére, C., Rose, D.W., Hooshmand, F., Aggarwal, A.K., and Rosenfeld, M.G. 2000. Allosteric effects of Pit-1 DNA sites on long-term repression in cell type specification. Science, 290: 1127-1131.

Shamblott, M.J., Axelman, J., Wang, S., Bugg, E.M., Littlefield, J.W., Donovan, P.J., Blumenthal, P.D., Huggins, G.R., and Gearhart, J.D. 1998. Derivation of pluripotent stem cells from cultured human premodial germ cells. Proc. Natl. Acad. Sci. USA, 95: 13726-13731.

Simeone, A., Acampora, D., Mallamaci, A., Stornaiuolo, A., D'Apice, M.R., Nigro, V., and Boncinelli, E. 1993. A vertebrate gene related to orthodendricle contains a homeodomain of the bicoid class and demarcates anterior neuroectoderm of the gastrulating mouse embryo. EMBO J., 12: 2735-2747.

Smith, A.G., Heath, J.K., Donaldson, D.D., Wong, G.G., Moreau, J., Stahl, M., and Rogers, D. 1988. Inhibition of pluripotential embryonic stem cell differentiation by purified polypeptides. Nature, 336: 688-690.

Smith, A.G. 1992. Mouse embryonic stem cells: their identification, propagation and manipulation. Semin. Cell. Biology, 3: 385-399.

Soodeen-Karamath, S., and Verrinder Gibbins, A.M. 2001. Apparent absence of oct $3 / 4$ from the chicken genome. Mol. Reprod. Dev., 58: 137148.

Starr, R., Novak, U., Wilson, T.A., Inglese, M., Murphy, V., Alexander, W.S., Metcalf, D., Nicola, N.A., Hilton, D.J., and Ernst, M. 1997. Distinct roles for leukemia inhibitory factor receptor a-chain and gp130 in cell type-specific signal transduction. J. Biol. Chem., 272: 1998219986.

Stewart, C.L., Kaspar, P., Brunet, L.J., Bhatt, H., Gadi, I., Kontgen, F., and Abbondanzo, S.J. 1992. Blastocyst implantation depends on maternal expression of leukemia inhibitory factor. Nature, 359: 76-79.

Suemori, H., Hashimoto, S., and Nakatsuji, N. 1988. Presence of the adenovirus E1A-like activity in preimplantation stage mouse embryos.
Mol. Cell. Biol., 8: 3553-3555.

Sylvester, I. and Schöler, H.R. 1994. Regulation of the Oct-4 gene by nuclear receptors. Nucleic Acids Res., 22: 901-911.

Taga, T. and Kishimoto, T. 1997. Gp130 and the interleukin-6 family of cytokines. Annu. Rev. Immunol., 15: 797-819.

Takai, H., Tominaga, K., Motoyama, N., Minamishima, Y.A., Nagahama, H., Tsukiyama, T., Ikeda, K., Nakayama, K., Nakanishi, M., and Nakayama, K.-I. 2000. Aberrant cell cycle checkpoint function and early embryonic death in Chk1(-/-) mice. Genes \& Dev., 14: 1439-1447.

Takeda, J., Seino, S., and I. Bell, G. 1992. Human Oct-3 gene family: cDNA sequences, alternative splicing, gene organization, chromosomal location, and expression at low levels in adult tissues. Nucleic Acids Res., 20: 4613-4620.

Takeda, K., Noguchi, K., Shi, W., Tanaka, T., Matsumoto, M., Yoshida, N., Kishimoto, T., and Akira, S. 1997. Targeted disruption of the mouse Stat3 gene leads to early embryonic lethality. Proc. Natl. Acad. Sci. USA, 94: 3801-3804.

Tanaka, S., Kunath, T., Hadjantonakis, A.-K., Nagy, A., and Rossant, J. 1998. Promotion of trophoblast stem cell proliferation by FGF4. Science, 282: 2072-2075.

Tanaka, Y., Patestos, N.P., Maekawa, T., and Ishii, S. 1999. B-myb is required for inner cell mass formation at an early stage of development. J. Biol. Chem., 274: 28067-28070.

Thomson, J.A., Kalishman, J., Golos, T.G., Durning, M., Harris, C.P., Becker, R.A., and Hearn, J. 1995. Isolation of a primate embryonic stem cell line. Proc. Natl. Acad. Sci. USA, 92: 7844-7848.

Thomson, J.A., Itskovitz-Eldor, J., Shapiro, S.S., Waknitz, M.A., Swiergiel, J.J., Marshall, V.S., and Jones, J.M. 1998. Embryonic stem cell lines derived from human blastocysts. Science, 282: 1145-1147.

Tomida, M., Yamamoto-Yamaguchi, Y., and Hozumi, M. 1984. Purification of a factor inducing differentiation of mouse myeloid leukemic M1 cells from conditioned medium of mouse fibroblast L929 cells. J. Biol. Chem., 259: 10978-10982.

Tomilin, A., Reményi, A., Lins, K., Bak, H., Leidel, S., Vriend, G., Wilmanns, M., and Schöler, H.R. 2000. Synergism with the coactivator OBF-1 (OCA-B, BOB-1) is mediated by a specific POU dimer configuration. Cell, 103: 853-864.

van Eijk, M.J., van Rooijen, M.A., Modina, S., Scesi, L., Folkers, G., van Tol, H.T., Bevers, M.M., Fisher, S.R., Lewin, H.A., Rakacolli, D., Galli, C., de Vaureix, C., Trounson, A.O., Mummery, C.L., and Gandolfi, F. 1999. Molecular cloning, genetic mapping, and developmental expression of bovine POU5F1. Biol. Reprod., 60: 1093-1103.

Viganó, M.A. and Staudt, L.M. 1996. Transcriptional activation by Oct-3: evidence for a specific role of the POU-specific domain in mediating functional interaction with Oct-1. Nucleic Acids Res., 24: 2112-2118.

Ware, C.B., Horovitz, M.C., Renshaw, B.R., Hunt, J.S., Liggitt, D., Koblar, S.A., Gliniak, B.C., McKenna, H.J., Papayannoupoulou, T., Thoma, B., Cheng, L., Donovan, P.J., Peschon, J.J., Bartlett, P.F., Willis, C.R., Wright, B.D., Carpenter, M.K., Davison, B.L., and Gearing, D.P. 1995. Targeted disruption of the low-affinity leukemia inhibitory factor receptor gene causes placental, skeletal, neural and metabolic defects and results in perinatal death. Development, 121: 1283-1299.

Wilder, P.J., Kelly, D., Brigman, K., Petrson, C.L., Nowling, T., Gao, Q.-S., McComb, R.D., Capecchi, M.R., and Rizzino, A. 1997. Inactivation of the FGF-4 gene in embryonic stem cells alters the growth and/or the survival of their early differentiation progeny. Dev. Biol., 192: 614629.

Williams, R.L., Hilton, D.J., Pease, S., Willson, T.A., Stewart, C.L., Gearing, D.P., Wagner, E.F., Metcalf, D., Nicola, N.A., and Gough, N.M. 1988. Myeloid leukemia inhibitory factor maintains the developmental potential of embryonic stem cells. Nature, 336: 684-687.

Xu, L., Lavinsky, R.M., Dasen, J.S., Flynn, S.E., Mclnerney, E.M., Mullen, T.-M., Heinzel, T., Szeto, D., Korzus, E., Kurokawa, R., 
Aggarwal, A.K., Rose, D.W., Glass, C.K., and Rosenfeld, M.G. 1998. Signal-specific co-activator domain requirements for Pit-1 activation. Nature, 395: 301-306.

Yeom, Y., Fuhrmann, G., Ovitt, C.E., Brehm, A., Ohbo, K., Gross, M., Hübner, K., and Schöler, H.R. 1996. Germline regulatory element of Oct-4 specific for the totipotent cycle of embryonal cells. Development, 122: 881-894.

Yoshida, K., Chambers, I., Nichols, J., Smith, A., Saito, M., Yasukawa, K., Shoyab, M., Taga, T., and Kishimoto, T. 1994. Maintenance of the pluripotential phenotype of embryonic stem cells through direct activation of gp130 signalling pathways. Mech. Dev., 45: 163-171.

Yoshida, K., Taga, T., Saito, M., Suematsu, S., Kumanogoh, A., Tanaka, T., Fujiwara, H., Hirata, M., Yamagami, T., Nakahata, T., Hirabayashi, T., Yoneda, Y., Tanaka, K., Wang, W.-Z., Mori, C., Shiota, K., Yoshida,
N., and Kishimoto, T. 1996. Targeted disruption of gp130, a common signal transducer for the interleukin 6 family of cytokines, leads to myocardial and hematological disorders. Proc. Natl. Acad. Sci. USA, 93: 407-411.

Yuan, H., Corbi, N., Basilico, C., and Dailey, L. 1995. Developmentalspecific activity of the FGF-4 enhancer requires the synergistic action of Sox-2 and Oct-3. Genes \& Dev., 9: 2635-2645.

Zwilling, S., Konig, H., and Wirth, T. 1995. High mobility group protein 2 functionally interacts with the POU domains of octamer transcription factors. $Е M B O J ., 14: 1198-1208$.

(Received for publication, May 2, 2001

and accepted May 25, 2001) 